\title{
The Missing Baby Bust: The Consequences of the COVID-19 Pandemic for Contraceptive Use, Pregnancy, and Childbirth Among Low-Income Women
}

\author{
Martha J. Bailey ${ }^{1}$ (D) Lea Bart ${ }^{2} \cdot$ Vanessa Wanner Lang $^{3}$
}

Received: 26 May 2021 / Accepted: 2 February 2022 / Published online: 2 March 2022

(c) The Author(s), under exclusive licence to Springer Nature B.V. 2022

\begin{abstract}
Multiple episodes in US history demonstrate that birth rates fall in response to recessions. However, the 2020 COVID-19 recession differed from earlier periods in that employment and access to contraception and abortion fell, as reproductive health centers across the country temporarily closed or reduced their capacity. This paper exploits novel survey and administrative data to examine how reductions in access to reproductive health care during 2020 affected contraceptive efficacy among lowincome women. Accounting for 2020's reductions in access to contraception and the economic slowdown, our results predict a modest decline in births of 1.1 percent in 2021 for low-income women. Further accounting for reductions in access to abortion implies that birth rates may even rise for low-income women. These results also suggest that already economically disadvantaged families disproportionately affected by the COVID-19 economy will experience a large increase in unplanned births.
\end{abstract}

Keywords Contraception · Long-acting reversible contraceptives (LARCs) · Fertility rates $\cdot$ Pregnancy $\cdot$ COVID-19 $\cdot$ Pandemic $\cdot$ Recession

\section{Introduction}

Multiple episodes in US history demonstrate that pregnancies and birth rates fall in response to economic uncertainty and downturns (Autor et al., 1990; Black et al., 2013; Buckles et al., 2019, 2021; Cherlin et al., 2013; Currie et al., 2014; Gemmill \&

Martha J. Bailey

marthabailey@g.ucla.edu

1 Department of Economics, University of California Los Angeles, 315 Portola Plaza, Bunche Hall 9349, Los Angeles, CA 90095, USA

2 Department of Economics, University of Michigan, Ann Arbor, USA

3 Population Studies Center, Institute for Social Research, University of Michigan, Ann Arbor, USA 
Hartnett, 2020; Kearney \& Levine, 2020a; Lindo, 2010; Schaller et al., 2020; Schneider \& Hastings, 2015). Using this historical relationship between recessions and birth rates, researchers projected early in the 2020 pandemic that changes in the demand for children would produce a massive baby bust, reducing US births by 300,000 to 500,000 (Kearney \& Levine, 2020a, b).

Consistent with this projection, a 2020 survey showed that many US women planned to delay or avoid childbearing as the economy slowed during the COVID19 pandemic (Lindberg et al. 2020a). Plans to reduce or delay childbearing were especially pronounced among lower-wage and minority women, who were disproportionately affected by the employment contraction (Bernstein \& Jones, 2020; Chetty et al., 2020), with 37 percent of women with incomes below 200 percent of the federal poverty line wanting to delay or avoid childbearing compared to 32 percent among women with higher incomes (Lindberg, Kost, et al. 2020b). Nearly half of Black and Hispanic women reported plans to delay or avoid childbearing, compared to just 28 percent of White women (Lindberg, Kost, et al. 2000b).

But the 2020 recession differed from previous recessions. One especially relevant difference is that access to contraception and reproductive health services fell, as health centers canceled or limited appointments in accordance with social distancing guidelines and patients limited in-person interactions. According to the $2020 \mathrm{Gutt}-$ macher Survey of Reproductive Health, 33 percent of women had to delay or cancel visiting their health care provider or had trouble getting their birth control due to the pandemic. These challenges were also more acute among poorer and minority women: 32 percent of women with incomes less than 200 percent of the poverty line reported worrying about affording or obtaining contraceptives during the pandemic relative to 23 percent of women with higher incomes, and 29 percent of Black women and 38 percent of Hispanic women reported increased worry, compared to only 23 percent of White women (Lindberg, Kost, et al. 2000b). In short, at the same time changes in the economy reduced the demand for children, the supply of contraceptives and access to abortion fell and likely moderated the baby bust (Bailey, 2010; Easterlin et al., 1980; Willis, 1973).

This paper quantifies the consequences of reduced access to reproductive health care due to COVID-19 restrictions using novel data from the Michigan Contraceptive, Access, Research, and Evaluation Study (M-CARES). When the COVID-19 pandemic reduced appointments at Planned Parenthood of Michigan (PPMI) health centers in March 2020, M-CARES was in the field and had been recruiting participants since August 2018. Like women hardest hit by the pandemic, patients at PPMI have lower rates of private health insurance, lower incomes, and are more likely to be racial and ethnic minorities (Planned Parenthood of Michigan, 2021; Planned Parenthood Federation of America, 2019, 2020). We refer to women seeking care at PPMI as "Title X patients," because they received subsidized services for reproductive health care through the Title X Public Health Service Act when M-CARES began. ${ }^{1}$ Participants in M-CARES reported which birth control methods they used in the month prior to their visit and consented to release their billing records at 1 Title X of the Public Health Service Act allocates federal funding to health centers to provide subsidized reproductive health services and contraception to low-income and uninsured women. In 2018, Title X served around 3.4 million women nationally. Planned Parenthood was one of Title X's largest providers in 2018, serving over 70 percent of Michigan's Title X patients. In 2019, Planned Parenthood 
PPMI. This combination of survey and administrative data provide a unique perspective on contraceptive method use before and after a typical Title $\mathrm{X}$ visit. These unique data allow us to calculate the changes in contraceptive efficacy and reductions in expected pregnancies resulting from a typical Title $\mathrm{X}$ visit. We then use this information to project changes in 2021 childbearing for the Title X population due to reductions in access to Title $\mathrm{X}$ health centers.

The results show that a typical Title $X$ visit resulted in contraceptive method changes expected to result in eight fewer pregnancies for every 100 women seeking care. Translating this change in pregnancies into expected births, we find that reductions in access to contraception due to COVID-19 restrictions should largely offset decreases in childbearing due to the COVID-19 economic slowdown for lowincome women. This methodology projects a much smaller decline in births of 1.1 percent in 2021 for Title X women than when accounting for economy alone. Further accounting for reductions in access to abortion due to COVID-19 restrictions implies that birth rates could even rise among low-income women in 2021. Taken together, these results anticipate that already disadvantaged families disproportionately affected by the COVID-19 economy will not experience a large baby bust but an increase in unplanned births.

\section{Background: How Access to Contraception Affects Use, Pregnancy, and Childbearing Among Low-Income Women}

In most high-income countries, governments make contraceptives free or inexpensive. In contrast, out-of-pocket costs for contraception in the US are closely linked to health insurance. Before the Patient Protection and Affordable Care Act (ACA) passed in 2010, US insurers often required patients to pay all or a significant part of the cost of birth control out-of-pocket. These costs for the highly effective, longacting reversible contraceptives (LARCs) such as IUDs and implants were prohibitively high. Before the ACA, women with insurance could be charged upwards of $\$ 1,000$ out-of-pocket for an IUD. The 2010 ACA included a "contraceptive coverage mandate" which required insurance plans to cover FDA-approved forms of contraception with no cost-sharing.

However, the ACA did not reduce prices for the roughly one third of non-elderly US women without private insurance (Kaiser Family Foundation, 2020). In some states, prices for contraception have increased over the last two decades as political initiatives increasingly link funding for contraception to the hot-button issue of abortion (Shorto, 2006). Since the ACA, state legislatures have reacted both by reducing

Footnote 1 (continued)

withdrew from the Title $\mathrm{X}$ program in response to Trump Administration requirements. Throughout this paper we use 2018 estimates of the Title X population as the best estimates for the Title X population and Planned Parenthood clients, and references to the Title X clinics include Planned Parenthood health centers, although Planned Parenthood is no longer in the program. See section III for more detail on how PPMI adjusted its fee scale and services after its withdrawal from Title X. 
their public spending on reproductive health and limiting the types of organizations eligible to receive public funds (NYT Editorial Board, 2019).

In 2019, the Trump Administration rewrote national funding guidelines to impose additional restrictions on the recipients of federal Title $\mathrm{X}$ funds, including a funding ban for providers referring patients to abortion providers and a requirement that recipients of federal funds physically separate sites that provide non-abortion reproductive health services from those that provide abortion. The new guidelines succeeded in causing large Title $\mathrm{X}$ providers like Planned Parenthood to withdraw from the Title X program in 2019. Even with the Trump Administration guidelines in effect for only five months, 844,803 fewer patients received care through Title X than in the previous year-2.7 million women in 2019 versus the 3.4 million served in 2018 (Fowler et al., 2020). Throughout 2020, Title X served just 1.3 million women, with 63 percent of the decrease relative to 2018 attributed to the new Title $\mathrm{X}$ guidelines (Fowler et al., 2021).

Several quasi-experimental studies suggest that changes in access to subsidized reproductive health services should affect the take-up of contraceptives and subsequent childbearing. Bailey's (2012) analysis of the expansion in federally funded family planning programs in the early years of Title $\mathrm{X}$ finds a reduction in US birth rates overall by 1.4 to 2.1 percent and by $19-30$ percent among the most disadvantaged women who took up Title X services. Kearney and Levine (2009) show that state-level expansions in Medicaid eligibility for family planning services in the 1990s and 2000s increased the use of contraception and reduced childbearing by 8.9 percent among newly eligible women. After Colorado-in collaboration with a donor-made LARCs free for all women in 2009, Lindo and Packham (2017) find that the teen birth rate fell by 6.4 percent within five years. Most recently, the ACA's requirement that private health insurance cover contraceptives has been shown to have decreased out-of-pockets costs and increased use of the most expensive and effective contraceptive methods (Becker, 2018; Carlin et al., 2016; Dalton et al., 2020; Heisel et al., 2018). Finally, and especially relevant for this study, Lu and Slusky (2019) show that closures of women's health centers in Texas increased birthrates by 1.2 percent. Similarly, Venator and Fletcher (2021) find that clinic closures in Wisconsin reduced the number of abortions by 30.7 percent and increased births by 3.2 percent.

While these studies show that increasing access and reducing the costs of contraceptives tends to increase take-up and reduce birth rates, their implications for the current pandemic are more difficult to gauge. One reason is that, even before the pandemic, many more low-income women are using LARCs than in the past. LARC use among low-income women using some type of contraception grew from 5.6 percent in 2008, just before the Colorado policy began, to 16.4 percent by 2014 (Bailey $\&$ Lindo, 2018). Higher use of LARCs allows women to delay their reproductive health visits during the pandemic with little consequence for pregnancy, because LARCs require fewer check-ups and no refills. A second reason is that the demand for children is different today than in the periods considered in earlier work. Today, women's market work is compensated at much higher rates than when the Title X program began in the 1970s. The booming economy of the 1990s and 2000s and revisions in public assistance programs likely imply differences in the demand for 
children. Finally, the Great Recession, which unfolded concurrently with Colorado's free LARC program and the implementation of the ACA, very likely had different effects on low-income workers than the 2020 COVID-19 economy, which lowered employment and increased women's childcare burdens simultaneously (AdamsPrassl et al., 2020; Alon et al., 2020a, b; Bick \& Blandin, 2020; Collins et al., 2020).

\section{Data and Methods: Quantifying Changes in Contraceptive Use at Title $X$ Health Centers}

This paper uses novel data from the Michigan Contraceptive Access, Research, and Evaluation Study (M-CARES). M-CARES is a randomized control trial designed to test how financial access to contraception affects the lives of low-income women in today's policy environment. This study was conducted at Planned Parenthood health centers in Michigan (PPMI) starting on August 20, 2018. M-CARES randomized half of study participants to receive vouchers to reduce the cost of contraceptives, while a control group received the PPMI standard of care and paid out-of-pocket according to PPMI's sliding scale. Eligibility for M-CARES required that women (1) were between ages 18 and 35, inclusive; (2) were at risk of unintended pregnancy (not currently pregnant, did not want to become pregnant in the next year, fecund, and had sex with men); and (3) had out-of-pocket costs for contraceptives (i.e., uninsured, or their insurance did not cover contraception). The study did not require that participants be visiting PPMI to obtain contraception-participants were recruited if they came to PPMI for any reason and met the eligibility criteria.

After Planned Parenthood withdrew from the Title X program in November 2019, PPMI used private donations and its own resources to subsidize its services using a slightly modified sliding scale that was around 20 percent less generous than before the withdrawal. ${ }^{2}$ Although women below the poverty line had no out-of-pocket costs previously, this changed on November 4, 2019, for those ages 22 or older. Because this group was only recruited after November 2019, they are underrepresented in the M-CARES sample. As described in subsequent sections, our analysis uses weights to address this data limitation.

\footnotetext{
${ }^{2}$ To the extent that withdrawal from Title X reduced women's ability to afford more expensive contraceptives (i.e., decreased contraceptive efficacy gains from a patient visit), our approach should understate the changes in efficacy due to COVID-19 restrictions relative to the fully funded Title X period. To test how much this change in fee scale affects our estimated efficacy rates, we compute changes in contraceptive efficacy for our sample for individuals recruited before and after November 4, 2019. During the Title $\mathrm{X}$ period, the average contraceptive efficacy increased by 0.10 after a PPMI visit (unweighted). After the Title X period, average contraceptive efficacy increased by 0.09 after a PPMI visit, which is not statistically different from the estimate in the Title $\mathrm{X}$ period $(\mathrm{p}=0.851)$. We, therefore, conclude that the impact of the withdrawal from Title $\mathrm{X}$ on our estimates is minimal.
} 


\section{Analytic Sample}

The goal of this paper is to quantify the effects of a typical Title $\mathrm{X}$ reproductive health visit on contraceptive efficacy. To that end, this analysis uses data only from the 1,405 women assigned to the control group who were recruited between August 20, 2018, and March 13, 2020, when recruitment was suspended due to safety concerns during the COVID-19 pandemic. These women received the Planned Parenthood standard of care and paid on the sliding scale, allowing us to characterize changes in the use of contraception that occur in the current policy environment without an experimental intervention. ${ }^{3}$ After excluding a handful of individuals who withdrew from the study, could not be linked to billing records, or who were missing responses about pre-visit birth control use or other key demographic characteristics, our final sample is 1,326 women. (See Appendix Figure A1 for details). In short, the sample is restricted to data collected prior to the COVID-19 pandemic and includes four and a half months of data collected after Planned Parenthood withdrew from Title X on November 4, 2019.

Table 1 shows the characteristics of the M-CARES sample (column 1) relative to the national population (column 2, 2017-2019 NSFG). The M-CARES sample is more likely to be in their early 20s, less likely to be a racial or ethnic minority, and more likely to have lower income (below 200 percent FPL) and be uninsured relative to the NSFG sample of 18- to 34-year-old women. Because the M-CARES sample was recruited at Planned Parenthood, its participants are (unsurprisingly) more likely to use contraception than the national population. The M-CARES sample differs less from the national population of Title X patients (column 3). While similar in age to Title X patients, the M-CARES sample is less likely to be Hispanic, have health insurance, and have incomes lower than the federal poverty line (FPL). The underrepresentation of very low-income and insured individuals reflects the study eligibility criterion 3-women below the FPL or with insurance were less likely to have out-of-pocket costs for contraception and, consequently, were less likely to be eligible to participate in M-CARES. The underrepresentation of Hispanic women reflects their underrepresentation in Michigan (see Appendix Table A1 for comparisons of Michigan to the US using data from the American Community Survey). The M-CARES sample also uses a different mix of contraception than the national sample, which likely reflects to some extent the fact that we measure contraceptive use in this table prior to their appointment, as opposed to after they see their provider. Later in the paper, we discuss reweighting our sample to resemble the national Title $\mathrm{X}$ population.

Although the sample for this paper is entirely drawn from one state, Michigan's reproductive health policies are shared with many other states. Michigan's Medicaid expansion program, Healthy Michigan, supplements the state's Medicaid program

\footnotetext{
3 The usual policy environment applies the Title $\mathrm{X}$ sliding scale to patient costs. Patients with incomes at 101-150 percent of the federal poverty line (FPL) pay 25 percent; with incomes $151-200$ percent pay 50 percent; with incomes 201-250 percent pay 75 percent; and with incomes above 250 percent pay 100 of PPMI prices.
} 
Table 1 Characteristics of analysis sample, women ages 18-34

\begin{tabular}{|c|c|c|c|c|}
\hline & (1) & (2) & (3) & (4) \\
\hline & $\begin{array}{l}\text { M-CARES } \\
\text { Sample }\end{array}$ & $\begin{array}{l}2017-9 \\
\text { NSFG }\end{array}$ & $\begin{array}{l}2018 \text { Title X } \\
\text { Patient Charac- } \\
\text { teristics }\end{array}$ & $\begin{array}{l}\text { MCARES } \\
\text { Reweighted to } \\
\text { Title X Char- } \\
\text { acteristics }\end{array}$ \\
\hline Observations & 2665 & 6141 & $\sim 3.4$ million & 2665 \\
\hline Age $18-19$ & 0.096 & 0.105 & 0.135 & 0.135 \\
\hline Age $20-24$ & 0.393 & 0.274 & 0.354 & 0.354 \\
\hline Age $25-29$ & 0.326 & 0.319 & 0.304 & 0.304 \\
\hline Age $30-34$ & 0.186 & 0.302 & 0.207 & 0.207 \\
\hline Non-Hispanic White & 0.673 & 0.565 & 0.333 & 0.333 \\
\hline Non-Hispanic Black & 0.135 & 0.154 & 0.195 & 0.195 \\
\hline Hispanic any race & 0.099 & 0.212 & 0.340 & 0.340 \\
\hline Other/Not Reported & 0.093 & 0.069 & 0.132 & 0.132 \\
\hline Less than $100 \% \mathrm{FPL}^{\mathrm{a}}$ & $0.080^{\mathrm{a}}$ & 0.236 & 0.667 & 0.667 \\
\hline $101-150 \%$ FPL & 0.398 & 0.129 & 0.149 & 0.149 \\
\hline $151-200 \%$ FPL & 0.246 & 0.115 & 0.073 & 0.073 \\
\hline $201-250 \%$ FPL & 0.124 & 0.080 & 0.035 & 0.035 \\
\hline $251+\% \mathrm{FPL}$ & 0.151 & 0.439 & 0.076 & 0.075 \\
\hline Insured & 0.073 & 0.863 & 0.583 & 0.583 \\
\hline Uninsured & 0.927 & 0.137 & 0.417 & 0.417 \\
\hline Sterile & $\mathrm{b}$ & 0.071 & 0.028 & $\mathrm{~b}$ \\
\hline LARC & 0.137 & 0.135 & 0.171 & 0.085 \\
\hline Birth control pills & 0.298 & 0.198 & 0.251 & 0.245 \\
\hline Condoms & 0.202 & 0.108 & 0.162 & 0.122 \\
\hline Withdrawal & 0.016 & 0.046 & 0.025 & 0.010 \\
\hline Other hormonal & 0.105 & 0.045 & 0.179 & 0.306 \\
\hline Other non-hormonal & 0.003 & 0.039 & 0.010 & 0.001 \\
\hline No method & 0.218 & 0.358 & 0.174 & 0.218 \\
\hline
\end{tabular}

M-CARES participants recruited from August 20th, 2018, to March 13th, 2020 ages 18-34. For M-CARES participants, contraceptive method is for the period prior to the Planned Parenthood visit. LARC includes implant and IUD. Condoms refer to male condoms. Other hormonal methods include the shot, patch, and ring. Other non-hormonal methods include vasectomy, female condoms, NFP, sponge, diaphragm, and spermicide. No method includes no reported method and abstinence. Estimates of the 2018 Title X participants are derived from Fowler et al. (2019), Exhibits 4, 7, 15, 16, and 18. The age distributions are the distribution of the ages of female Title $X$ users between ages 18 and 34, calculated using Exhibit 4. Race distributions are for female Title X users of all ages, calculated using Exhibit 7. Income distributions are for all Title X users with income above 100\% of FPL, calculated using Exhibit 15

${ }^{a}$ This group is excluded from the M-CARES sample before November 2019 and so is underrepresented ${ }^{\mathrm{b}}$ This group is excluded from the M-CARES sample because these women are not at risk of pregnancy

and covers women who are not pregnant who earn up to 133 percent of the federal poverty line. Michigan offers a 6 percent state EITC and has per capita spending on public welfare close to the national average (US Census Bureau, 2019). As of 2019, 
Michigan's childcare subsidy assistance had the lowest initial eligibility threshold nationally (Dwyer et al., 2020).

\section{Computing Changes in Expected Childbearing from Reductions in Title X Services}

This paper computes the expected change in contraceptive use before and after a typical PPMI appointment in several steps. First, we calculate the expected change in contraceptive efficacy during a typical Title $\mathrm{X}$ visit. This allows us to compute the change in the expected number of pregnancies, holding sexual activity fixed. Second, we compute the pregnancy-to-birth transition rate using the NSFG, which accounts for the fact that not all pregnancies result in live births. Third, we use estimates from the literature to approximate changes in the demand for children that covary with the business cycle. Our last step combines the estimated increase in childbearing (due to reductions in reproductive health care) with the estimated decrease in childbearing (due to the economic downturn) to predict the change in births for Title $\mathrm{X}$ women in 2021 relative to 2020 . The following discussion describes each of these steps in more detail.

\section{Computing Changes in Contraceptive Efficacy}

A key outcome in this study is the change in contraceptive efficacy, which describes how patients' choices of contraception changed during a typical visit to PPMI. We calculate this change using two data sources. A screening survey determined eligibility for M-CARES and asked eligible women seeking care at PPMI about their use of contraception in the month before they came to PPMI. All study participants completed the screening survey. The screening survey is complemented by PPMI billing records, which all study participants consented to allow PPMI to release records to M-CARES for research purposes. These records characterize any transactions that the patient had with PPMI during and after her visit and can be linked to survey responses for over 99.9 percent of participants. Combining these data sources provides a highly accurate description of birth control method use before and after the visit to PPMI.

We compute contraceptive efficacy as 1-the CDC's expected one-year method failure rate with typical use. The expected contraceptive failure rates represent the share of women who are expected to experience a pregnancy within one year with typical use (Trussell, 2011). CDC failure rates range from 0.0005 for a subdermal implant, 0.09 for birth control pills, and 0.18 for the male condom. Women who report using multiple forms of contraception are assigned the efficacy rate corresponding to their most effective method. For example, if the respondent reported using both condoms and birth control pills, we assign contraceptive efficacy as 0.91 (1-0.09), which uses the failure rate of typical use associated with birth control pills.

Pre-visit efficacy is calculated using the contraceptive methods reported by the patient in the pre-visit survey, which is taken by all women who enroll. Post-visit efficacy is calculated using PPMI billing records. If women purchased contraceptives from PPMI up to 100 days after their visit, we code the post-visit method to 
be the method purchased. We use purchases up to 100 days after a visit, because some methods require a follow-up. For instance, switching to an IUD requires both a pregnancy test and typically a follow-up visit. For all women with no contraceptive purchases in PPMI data, we assume they continued using the method reported in the pre-visit survey. For instance, if a woman reported using birth control pills before her visit in the survey but did not purchase any pills, we assume she continued using birth control pills (presumably purchased before her visit). Women who report using abortion, miscarriage, Plan B, or abstinence as a method are coded as using "no preventative method."

Empirical evidence supports the assumption that if respondents are missing data on contraceptive purchases in the post-period, they are using their pre-visit method. Using available survey responses for women who report using the pill before their PPMI visit and did not purchase birth control pills in PPMI billing records, 98 percent report still being on the pill immediately after their appointment in our postvisit survey. This is consistent with Planned Parenthood's policy that patients are permitted to purchase up to 13 packs of pills when they receive a new prescription. Women using the pill prior to their PPMI visit may have a supply of pills at home and continue using the pill despite not filling a new prescription. While we do not know the continuation rate for women who do not have billing records and did not respond to our survey after their appointment, the high rate of pill continuation among women using the pill at enrollment for the women we do observe suggests our assumption is reasonable.

Given the differences between our study population and the Title X population nationally, we use entropy balancing to reweight the sample such that the age, race/ ethnicity, insurance, and income characteristics of M-CARES participants match those in the national Title X population captured in the 2018 Health and Human Services (HHS) Annual Report (Fowler et al., 2019; Hainmueller, 2011). ${ }^{4}$ We generate 95-percent confidence intervals by bootstrapping our entropy-balanced estimates using replacement (1000 replications). Identifying the 0.025 and 0.975 percentiles from the distribution of 1000 estimates provides the 95-percent confidence interval (Efron \& Tibshirani, 1993). Table 1 shows that the reweighted M-CARES sample (column 5) is similar in key characteristics to the 2018 Title X reports (column 4). This reweighting ensures that the M-CARES sample resembles the age, race, insurance, and income characteristics of the Title X patients, although it does not guarantee that unobserved Title X patients characteristics are also balanced. Importantly, we do not reweight the M-CARES sample to resemble the Title X patients in terms of contraceptive use, because contraceptive use of Title X patients results from their appointment at a Title $\mathrm{X}$ provider. Accordingly, the reweighted M-CARES sample is less likely to use birth control and LARCs, as measured prior to their visit, than the 2018 Title X patient population. See Online Appendix B for more details about reweighting the M-CARES sample to resemble national Title $\mathrm{X}$ patient characteristics.

\footnotetext{
${ }^{4}$ Unfortunately, we do not have microdata for all Title $\mathrm{X}$ patients, which means that we cannot use inverse propensity score reweighting.
} 


\section{Translating Expected Pregnancies into Expected Births}

In 2008, an estimated 65 percent of pregnancies resulted in a live birth, 17 percent in miscarriage, and 18 percent in abortion (Ventura et al., 2012; Zolna \& Lindberg, 2012). However, the likelihood that a pregnancy will end in a live birth may differ for the M-CARES sample of low-income women and also have changed between 2008 and today.

The 2017-2019 NSFG allows us to estimate the share of pregnancies that result in childbirth (pregnancy-to-birth transition rate) for the Title X population. For every woman with a pregnancy that began at least 10 months before the NSFG interview and no earlier than 2015, the NSFG's pregnancy history identifies her contraceptive method at the time of conception and the outcome of the pregnancy (e.g., live birth, miscarriage, abortion), ${ }^{5}$ as well as information on age, race, poverty status, and health insurance at the time of the interview. For women with multiple completed pregnancies in this time period we use the contraceptive method from their most recent pregnancy. For women without a completed pregnancy during this period, we use contraceptive method as of the January of the year before they were interviewed. We then use entropy balancing to reweight the NSFG sample to match the Title X population in terms of contraceptive method type, age, race/ethnicity, income distributions, and insurance status. In particular, reweighting to match the distribution of contraceptive use accounts for the fact that Title $\mathrm{X}$ patients are more likely to use birth control and more likely to desire avoiding pregnancy and childbirth than the average woman in the population. A final step in this process is that we inflate reported abortions and miscarriages to account for well-known underreporting in the NSFG (Lindberg et al., 2020a; Linnakaari et al., 2019). Appendix Table C1 shows balance in characteristics after this reweighting and a resulting pregnancyto-birth transition rate for Title $\mathrm{X}$ patients of 0.479 , which is shown in Appendix Table C2. The reweighted estimate indicates that 47.9 out of every 100 pregnancies to Title $\mathrm{X}$ clients resulted in a live birth. This rate is slightly lower than what we estimate for the overall population in the 2017-2019 NSFG (49.5 after adjustments for misreporting). ${ }^{6}$ The true transition rate may also differ because access to abortion changed during the pandemic. Many southern and midwestern states declared abortion a non-essential service in 2020, which effectively created temporary abortion bans. ${ }^{7}$ In addition, 19 states required medication abortion to be issued in person by

\footnotetext{
${ }^{5}$ We exclude pregnancies that did not begin at least 10 months before the interview because the outcomes are unknown.

${ }^{6}$ Reweighting on contraceptive method type is primarily responsible for the lower the transition rate for the Title X population relative to the overall population. If we reweight the NSFG so that all characteristics except for birth control use (income, insurance, age, and race) correspond to the Title X population, we estimate a pregnancy-to-birth transition rate of 58.7 percent, reflecting a younger, lower-income, less white, and more uninsured Title $\mathrm{X}$ population relative to national levels. However, if we reweight using these characteristics and pre-visit contraceptive use, our estimate falls to 47.9 percent, which we report.

7 See https://www.kff.org/coronavirus-covid-19/issue-brief/state-action-to-limit-abortion-access-duringthe-covid-19-pandemic (accessed October 22, 2021).
} 
a clinician, which was difficult or impossible to arrange during the pandemic. ${ }^{8}$ If the true Title X pregnancy-to-birth transition rate is higher than we estimate, reflecting lower access to abortion care during the pandemic, our results will underestimate the increase in births to Title $\mathrm{X}$ women due to changes in the supply of contraception during COVID-19. Under the assumption that COVID-19 shutdowns affected abortion access similarly to contraceptive access, the pregnancy-to-birth transition rate could be as high as 73.4 percent, which would reflect all pregnancies ending in either birth or miscarriage. (See Appendix C for details).

\section{Computing Changes in the Demand for Children}

Up to this point, our calculations of efficacy, pregnancy, and childbirth implicitly hold the demand for contraception and childbirth constant. That is, they assume that women make no other adjustments in their sexual activity or contraceptive use within the year aside from what takes place during their PPMI visit. However, research documents that recessions could both increase and decrease childbearing in theory. On the one hand, childbearing may increase because the opportunity cost of having a child falls as employment opportunities or wages contract. On the other hand, reductions in income and increases in economic uncertainty that come during recessions tend to decrease childbearing. Empirically, the latter effect tends to dominate, and fertility rates vary positively with the business cycle in the short run (Currie \& Schwandt, 2014; Lindo, 2010; Schneider, 2015). Improvements in labor market conditions for women specifically have small or no effects on childbearing, suggesting that the opportunity cost of childbearing decreases fertility rates around as much as the income effect increases it for this group (Schaller, 2016). Overall, we expect that the COVID-19 pandemic reduced the demand for children.

To account for likely shifts in the demand for contraception and children, our analysis follows Kearney and Levine's (2020a) methodology, which estimates childbearing responses based on previous recessions. The purpose of following their methodology is to account for the extent women may have changed other behaviors to reduce childbearing, even if they could not obtain their desired contraceptives (e.g., abstained from sex). While Kearney and Levine's methodology was developed for the US population overall and is not specific to this paper's sample of lowincome women, it is a transparent and straightforward approximation to measure shifts in the demand for children on childbearing.

Their calculation assumes that a one-percentage-point increase in the unemployment rate will reduce birth rates by one percent. Because the unemployment rate for the Title $\mathrm{X}$ population increased by approximately 8 percentage points during the COVID-19 downturn (Chetty et al., 2020), this methodology anticipates an 8 percent decrease in births for the Title $\mathrm{X}$ population due to reductions in the demand for children. ${ }^{9}$ Given the

\footnotetext{
8 See https://www.guttmacher.org/state-policy/explore/medication-abortion (accessed October 22, 2021).

${ }^{9}$ Chetty et al. (2020) estimate a 20 percent decline in employment for low wage workers due to COVID19 as of October 2020. Using an estimated base employment rate of 39.5 percent for Title X workers (see Online Appendix D), calculated using the March 2020 CPS, a 20 percent decline in employment implies
} 
baseline estimate of 178,874 births to Title $\mathrm{X}$ patients, ${ }^{10}$ an 8 percent reduction implies about 14,350 fewer births to Title X patients nationally as a result of the COVID-19 employment contraction for this group. In addition, Kearney and Levine (2020a) assume that uncertainty and anxiety due to the pandemic will reduce births by another 15 percent. With this further adjustment, our estimate of the reduction in childbearing due to demand factors rises to 16,251 fewer births. Online Appendix D provides all details underlying this calculation.

Our analysis adjusts for changes in the demand for births, including changes in preferences, sexual activity, or behavior in response to the pandemic economy, by subtracting the 16,251 expected decrease in births due to reductions in the demand for children from the expected increase in births due to the change in access to contraception.

\section{Results: How Title X Health Centers Affect Contraceptive Efficacy and Birth Rates}

Table 2 presents the expected changes in contraceptive use during a typical visit to PPMI (for comparison, unweighted frequencies and distributions appear in Appendix Tables A2 and A3, and weighted frequencies underpinning calculations in Table 2 are presented in Table A4). Pre-visit methods are presented in the first column and ordered from the most to least effective according to CDC's expected oneyear method failure rate with typical use (presented in parentheses), and post-visit methods are captured in columns. The final three rows show the share of women who switched to more effective methods by their pre-visit method. For instance, among women using an implant before their visit to PPMI, 51 percent continued this method and 49 percent switched to a less effective method. For women who did not purchase another method, we conservatively assume they continue to use their previsit method. Aggregating across all methods, roughly 79 percent of women stayed on the same method after their visit, and 19 percent switched to a more effective method. Only 2 percent of women switched to a less effective method.

Table 3 summarizes the average change in contraceptive efficacy during a typical visit to PPMI as captured by 1 -the CDC failure rate. We present estimates for the M-CARES sample as well as estimates of this sample weighted to match the age, race, income, and insurance characteristics of the Title X patient population nationally.

Footnote 9 (continued)

a 7.9 percentage-point decrease in the employment rate. Assuming the share of the Title X population in the labor force remains constant, this translates to a 7.9 percentage-point increase in the unemployment rate for the Title $\mathrm{X}$ population due to COVID-19.

${ }^{10}$ The number of female Title $X$ and Planned Parenthood users (about 3.4 million in 2018) multiplied by the estimated birth rate for Title X clients obtained from the NSFG (51.9 births per 1,000 women) implies that Title $X$ and Planned Parenthood clients gave birth to about 180,000 children per year on average. See Online Appendix D. 


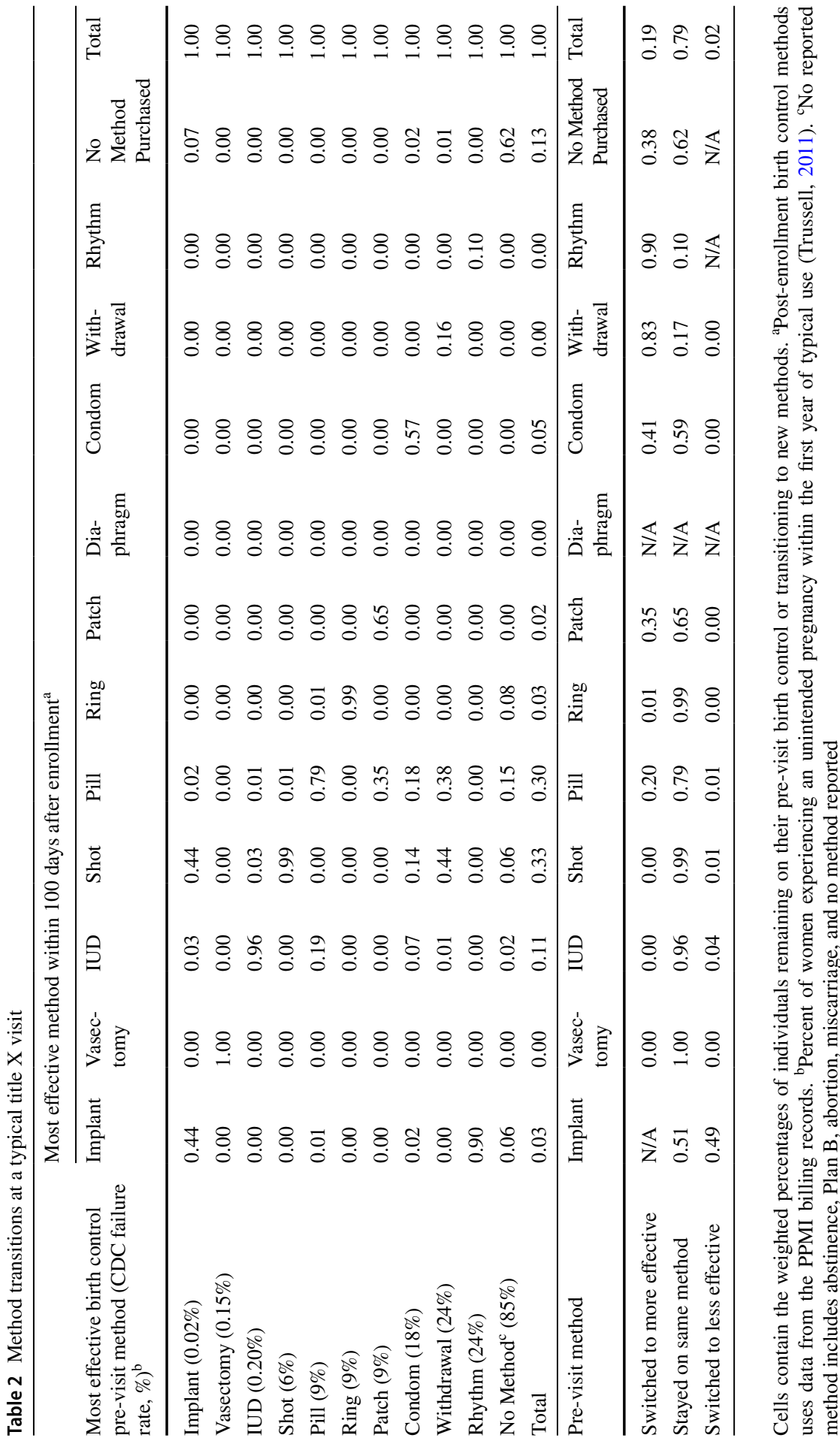


Table 3 Changes in contraceptive efficacy and expected pregnancies at a typical Title X visit

\begin{tabular}{llc}
\hline & Unweighted & Weighted \\
\hline Average efficacy of contraceptives before visit & $0.70(0.68,0.72)$ & $0.73(0.64,0.79)^{*}$ \\
Average efficacy of contraceptives after visit & $0.80(0.78,0.82)$ & $0.81(0.75,0.87)^{*}$ \\
Change in efficacy during visit & $0.10(0.07,0.12)$ & $0.08(0.05,0.15)^{*}$ \\
Expected new pregnancies if Title X health centers close for 12 months & \\
Female title X patients in Michigan (N=54,981) & 5498 & 4398 \\
All female title X patients in the US (N=3,446,504) & 344,650 & 275,720 \\
\hline
\end{tabular}

Sample includes women 18-34 recruited by M-CARES who were randomly assigned to the control group. Observations missing race, age, income, or pre-visit method use are excluded from the analysis. *Confidence intervals for weighted estimates are estimated using a bootstrap with 1000 iterations. Expected pregnancies are obtained by multiplying the population by the change in average efficacy. See text for more details on M-CARES sample and reweighting procedure

Prior to their PPMI visit, women's contraceptive efficacy averaged 0.73, indicating that pregnancies are expected for 27 out of 100 women within a year. After a visit to PPMI, contraceptive efficacy increased to an average of 0.81 , indicating that only 19 pregnancies are expected to occur within one year for every 100 women. 95-percent confidence intervals in parentheses capture the uncertainty associated with each estimate. Combining the before and after efficacy measures shows that a typical visit to PPMI is expected to reduce pregnancies by 8 per 100 women within the year using the weighted estimates. Closing all Title X health centers in Michigan for one year would, therefore, be expected to result in an additional 4,398 pregnancies for the state's 54,981 Title X patients. Alternatively, scaling these estimates by the 3,446,504 female Title X patients nationally in 2018, these estimates predict that a closure of all Title X health centers for one year would lead to 275,720 additional pregnancies. Using the pregnancy to childbirth conversion rate of 47.9 percent from section III.B.2 implies that a one-year shutdown of Title $\mathrm{X}$ health centers would increase births in Michigan by 2170 and births nationally by 132,070 . Similar calculations based on efficacy changes by subpopulations can be found in Appendix Tables A5 and A6.

Table 4 uses several data sources to refine these estimates to reflect the actual magnitude and duration of COVID-19 health center reductions in capacity. According to PPMI administrative records for health centers in M-CARES, PPMI had 60 percent fewer patient visits in April 2020 than in February 2020 due to COVIDrelated capacity reductions and social distancing requirements. Assuming this 60 percent reduction in capacity was similar at Title $\mathrm{X}$ health centers across the country in states with lockdowns similar to Michigan's for the first 3 months of the pandemic, we expect that reduced health center capacity during the first 3 months of COVID-19 shutdowns should result in 27,090 additional pregnancies among the Title $\mathrm{X}$ population and 12,976 more live births. ${ }^{11}$ Assuming half the reduction in

\footnotetext{
11 This calculation is as follows: $3,446,504$ Title $\mathrm{X}$ clients $* 0.08$ efficacy change $* 3 / 12$ of a year $*$ 0.6 reduction $* 0.665$ of US population under strict business closure and stay-at-home orders similar to Michigan.
} 
Table 4 Expected deviations in 2021 pregnancies and births from reductions in Title X health center operations

A. Deviation in 2021 pregnancies

\begin{tabular}{lll}
\hline & Michigan & Nationally \\
\hline Title X health centers shutdown for one year & 4398 & 275,720 \\
Estimate of actual Title X capacity reductions & 660 & 29,964 \\
\hline
\end{tabular}

B. Deviation in 2021 births

\begin{tabular}{|c|c|c|c|c|}
\hline & \multicolumn{2}{|c|}{ No change in abortion access } & \multicolumn{2}{|c|}{ No abortion access } \\
\hline & Michigan & Nationally & Michigan & Nationally \\
\hline \multirow{2}{*}{$\begin{array}{l}\text { Title X health centers } \\
\text { shutdown for one year }\end{array}$} & 2107 & 132,070 & 3228 & 202,379 \\
\hline & $73.8 \%^{*}$ & $73.8 \%^{*}$ & $113.1 \%^{*}$ & $113.1 \%^{*}$ \\
\hline \multirow{2}{*}{$\begin{array}{l}\text { Estimate of actual Title X } \\
\text { capacity reductions }\end{array}$} & 316 & 14,353 & 484 & 21,994 \\
\hline & $11.1 \%^{*}$ & $8.0 \%^{*}$ & $17.0 \%{ }^{*}$ & $12.3 \%^{*}$ \\
\hline
\end{tabular}

C. Predicted changes in 2021 births after accounting for reductions in the demand for children

\begin{tabular}{llllll}
\hline & \multicolumn{2}{l}{ No change in abortion access } & & \multicolumn{2}{l}{ No abortion access } \\
\cline { 2 - 3 } \cline { 5 - 6 } & Michigan & Nationally & & Michigan & Nationally \\
\hline $\begin{array}{l}\text { Changes in births net of } \\
\text { shifts in demand }\end{array}$ & 57 & -1898 & 225 & 5743 \\
& $2.0 \% *$ & $-1.1 \% *$ & & $7.9 \% *$ & $3.2 \% *$ \\
\hline
\end{tabular}

Each cell in Panel A represents how many fewer pregnancies are expected if Title $\mathrm{X}$ health centers saw the corresponding reduction in capacity, assuming that the average improvement in contraceptive efficacy of going to a Title $\mathrm{X}$ health center appointment is 0.08 . This increase in efficacy comes from our nationally representatively weighted estimate from the efficacy table. Panel B represents the expected number of births that would result from these pregnancies, which is obtained by multiplying the expected pregnancies by a pregnancy-to-birth transition rate. We present estimates for two such rates: $47.9 \%$, which is directly estimated from the NSFG as described in the text, and $73.4 \%$, which additionally assumes that abortion became temporarily unavailable during the COVID-19 shutdowns and all pregnancies ended in birth or miscarriage. Panel $\mathrm{C}$ subtracts the anticipated reduction in births due to the pandemic slowdown in the economy from the increases in births in panel B

* Numbers in italics are percent changes relative to the estimated number of baseline births to the Title $\mathrm{X}$ population, which was 2854 in Michigan and 178,874 nationally

capacity at Title $\mathrm{X}$ health centers was in counties with less stringent lockdowns (14 percent of the US population) for the first 3 months of the pandemic, we expect that reduced health center capacity resulted in 2874 additional pregnancies for the Title X population and 1377 more births. ${ }^{12}$ Together, Table 4 shows that these

\footnotetext{
12 This second calculation is identical to the first except for that it uses information that 13.9 percent of US residents were in safer-at-home order counties which experienced smaller reductions in capacity. Information on safer-at-home orders and lockdowns comes from https://www.naco.org/resources/featu red/counties-and-covid-19-safer-home-orders (downloaded January 14, 2021).
} 
figures imply 29,964 more pregnancies (panel A, row 2, column 2). Using the NSFG estimate of the pregnancy-to-birth transition rates of 47.9 percent, we expect the COVID-19 reductions in reproductive health services to result in 14,353 more births for the Title X population in 2021 (panel B, column 2), an increase of 8.0 percent from the baseline birthrate. At most, if the shutdown also eliminated access to abortions and all pregnancies ended in birth or miscarriage, this would raise the estimate to 21,994 additional births, an increase of 12.3 percent over the baseline birth rate (panel B, column 4).

The estimates assume contraceptive efficacy and abortion access are the only factors changing during the COVID-19 shutdowns. However, Kearney and Levine's (2020a) historical estimates show that the COVID-19 economy should reduce the demand for children through other channels and, potentially, through lower rates of sexual activity. Subtracting the expected decrease in births of 16,251 due to demand changes from employment, uncertainty and anxiety (see section III.B.3) from the 14,353 expected increase in births from changes in the supply of contraception, the net change in births to the Title $\mathrm{X}$ population due to COVID-19 is a decrease of 1.1 percent, or 1898 births below a baseline of 178,874 (panel C, column 2). An alternative calculation assumes that the COVID-19 shutdowns eliminated access to abortion and that all pregnancies result in childbirth or miscarriage. In this case, we subtract the expected decrease in births due to demand changes from the 21,994 additional births expected increase in births from changes in the supply of contraception, which results in a net change in births to the Title X population of 3.2 percent, or 5743 births above the baseline (panel C, column 4).

How much of these changes in childbearing represent mistimed versus unwanted births? Although this cannot be directly computed, the M-CARES baseline survey asks women about their ideal number of children using a series of questions developed by Coombs (1974). ${ }^{13}$ For the 83 percent of women who respond to the baseline survey, around one quarter had reached their ideal number of children. As is well documented, ideals are not always realized, but these seem like reasonable numbers to use as a guide. These responses suggest that around 75 percent of births due to reductions in Title $\mathrm{X}$ health center operations are at least one year earlier than desired, while 25 percent of the births that occur due to reductions in Title $\mathrm{X}$ health center operations would not have occurred in the future.

\section{Study Limitations}

This analysis has several important limitations. First, our sample only represents women who elected to participate in the M-CARES randomized control trial. Although 75 percent of the women M-CARES approached chose to participate,

\footnotetext{
13 The Coombs scale introductory question is, "For you personally, what would be the ideal number of children you would like to have?" The respondent is then asked systematically about what-if the ideal number is not available - the next choice would be in order to assess preferences not captured in the first response.
} 
this study's conclusions could be altered if the typical visit for the 25 percent of women who opted out resulted in different changes in contraceptive efficacy.

Second, we assume that changes in contraceptive efficacy from a visit to PPMI are comparable to those at other types of Title $\mathrm{X}$ health centers by using the term, "typical Title X visits," throughout the paper. However, Planned Parenthood health centers have been found to provide more timely and accessible contraceptive care than other Title X providers, such as health departments and federally qualified health centers (FQHCs). Planned Parenthood is more likely to provide same-day appointments, on-site pill dispersal, same-day IUD or implant insertion, and the full range of contraceptive methods than health departments or FQHCs (Hasstedt, 2017). If these differences result in larger contraceptive efficacy changes for a typical PPMI visit than to other Title $\mathrm{X}$ providers, our calculations could overestimate the average changes in efficacy and the resulting increase in births due to reductions in Title $\mathrm{X}$ health centers operations. Because Planned Parenthood accounted for 41 percent of all contraceptive clients at Title $\mathrm{X}$ funded health centers prior to their exit from the Title $\mathrm{X}$ program, the differences between Planned Parenthood visits alone and the average of Planned Parenthood and Title X visits is likely minimal (Frost et al., 2017).

Finally, we follow Kearney and Levine's (2020a) methodology in using previous recessions to quantify the change in the demand for children. To the extent that the childbearing response among low-income women during the COVID-19 economy (e.g., due to differential changes in women's employment, childcare availability, and school closures) differs from responses to past recessions, this methodology may misrepresent shifts in demand during the COVID-19 downturn.

\section{Conclusions: Slight or No Decline in 2021 U.S. Birth Rates and Large Increases in Unplanned Childbirth}

Using a novel dataset, this paper describes changes in contraceptive efficacy that occurs at a typical Title $\mathrm{X}$ visit and predicts changes in birth rates for Title $\mathrm{X}$ women in 2021. Accounting for the magnitude and duration of the COVID-19 reductions in health center access, we expect only around 2000 fewer births, or a 1.1 percent decline, for this disadvantaged population-much less than the projected $8 \%$ or 300,000 births for the US population overall (Kearney and Levine's (2020a, b). Unless couples use non-medical contraceptive methods like abstinence, withdrawal, or condoms with the same effectiveness as medical/hormonal alternatives, the year 2021 could experience a smaller baby bust than projected. Another conclusion is that shifts in both the demand for children and the availability of reproductive health services amid the pandemic should increase the share of pregnancies and births that are unplanned for low-income, uninsured women.

Although our estimates are specific to the Title $\mathrm{X}$ population, the magnitudes of changes in birth rates in this paper align closely with recent figures released for the entire US population. Provisional data from the National Vital Statistics System 
show that US birth rates from the first half of 2021 were down by 1.9 percent relative to the first half of 2020 — a figure only slightly larger than our estimated 1.1 percent for the Title $\mathrm{X}$ population and much smaller than anticipated. ${ }^{14}$ Although outside the scope of our data, a reasonable expectation is that changes in access to contraception and abortion may moderate the anticipated 2021 COVID-19 baby bust for the broader population as well.

Beyond understanding the implications of the COVID-19 economic downturn for childbearing, these findings have implications for state and national reproductive health policy. Over the last decade, many state legislatures have limited funding for reproductive health care through Medicaid and Title X as well as through state programs. At the national level, the Trump administration revised 2019 guidelines for the Title X program, which resulted in more than 1000 health centers in 34 states withdrawing from Title $\mathrm{X}$-sites that had served more than 1.5 million patients in the year before the rule took effect (National Family Planning \& Reproductive Health Association, 2020). In the absence of new funding or providers, we expect that reductions in funding for Title $\mathrm{X}$ reproductive health services should have similar implications for the pregnancies and birthrates of low-income women.

Supplementary Information The online version contains supplementary material available at https://doi. org/10.1007/s11113-022-09703-9.

Acknowledgements The M-CARE study was supported through grants awarded by Arnold Ventures (AV) and the NICHD (R01HD100438). Bart's research on this project was supported by the Eunice Kennedy Shriver National Institute of Child Health \& Human Development of the National Institutes of Health under Award Number T32HD007339. The content is solely the responsibility of the authors and does not necessarily represent the official views of the National Institutes of Health or of Planned Parenthood Federation of America, Inc. We gratefully acknowledge the use of the services and facilities of the Population Studies Center at the University of Michigan (P2CHD041028) and the California Center for Population Research at UCLA (P2CHD041022). We are grateful for excellent research support by Suni Jo Roberts and Mari Hashimoto. We also thank Planned Parenthood of Michigan (PPMI), including Melissa Fuller and Martha Nokken, for helping us understand PPMI processes and facilitating access to electronic medical records; and NORC, including Sheri Hamilton, Karen Veldman, Lauren Seward, Chet Bowie, and Lisa Blumerman, for their expert management of the field interviewers, survey, and the recruitment process.

\section{References}

Adams-Prassl, A., Boneva, T., Golin, M., \& Rauh, C. (2020). Inequality in the Impact of the Coronavirus Shock: Evidence from Real Time Surveys. Retrieved from www.iza.org

Alon, T., Doepke, M., Olmstead-Rumsey, J., \& Tertilt, M. (2020a). The impact of COVID-19 on gender equality. Retrieved from http://www.nber.org/papers/w26947

Alon, T., Doepke, M., Olmstead-Rumsey, J., Tertilt, M., Thank, W., Bardoczy, B., Zymek, R. (2020b). This time it's different: The role of women's employment in a pandemic recession. Retrieved from http://www.nber.org/papers/w27660

\footnotetext{
${ }^{14}$ Authors' calculations based on provisional data from NVSS on monthly live births, available at https://www.cdc.gov/nchs/nvss/vsrr/provisional-tables.htm.
} 
Autor, D., Dorn, D., \& Hanson, G. (1990). When work disappears: manufacturing decline and the falling marriage market value of young men. AER Insights, 2019(2), 161-178. https://doi.org/10. 1257/aeri.20180010

Bailey, M. J. (2010). "Momma's Got the Pill": how anthony comstock and griswold v. connecticut shaped US childbearing. American Economic Review, 100(1), 98-129. https://doi.org/10.1257/ aer

Bailey, M. J. (2012). Reexamining the impact of family planning programs on us fertility: Evidence from the war on poverty and the early years of title X. American Economic Journal: Applied Economics, 4(2), 62-97. https://doi.org/10.1257/app.4.2.62

Bailey, M. J., \& Lindo, J. M. (2018). Access and use of contraception and its effects on women's outcomes in the United States. In S. L. Averett, L. M. Argys, \& S. D. Hoffman (Eds.), Oxford Handbook of Women and the Economy. https://doir.org/https://doi.org/10.1093/oxfordhb/9780190628 963.013.19.

Becker, N. (2018). The impact of insurance coverage on utilization of prescription contraceptives: Evidence from the affordable care act. Journal of Policy Analysis and Management, 37(3), 571-601. https://doi.org/10.1002/pam.22064

Bernstein, J., \& Jones, J. (2020). The Impact of the COVID19 recession on the jobs and incomes of persons of color. Retrieved from https://www.cbpp.org/research/full-employment/the-impact-of-thecovid19-recession-on-the-jobs-and-incomes-of-persons-of

Bick, A., \& Blandin, A. (2020). Real-time labor market estimates during the 2020 coronavirus outbreak. SSRN Electronic Journal. https://doi.org/10.2139/ssrn.3692425

Black, D. A., Kolesnikova, N., Sanders, S. G., \& Taylor, L. J. (2013). Are children "Normal"? The Review of Economics and Statistics, 95(1), 21-33.

Buckles, K., Guldi, M. E., \& Schmidt, L. (2019). Fertility Trends in the United States, 1980-2017: The Role of Unintended Births. Retrieved from National Bureau of Economic Research website: http:// www.nber.org/papers/w25521

Buckles, K., Hungerman, D., \& Lugauer, S. (2021). Is Fertility a leading economic indicator? The Economic Journal, 131(634), 541-565. https://doi.org/10.1093/ej/ueaa068

Carlin, C. S., Fertig, A. R., \& Dowd, B. E. (2016). Affordable care act's mandate eliminating contraceptive cost sharing influenced choices of women with employer coverage. Health Affairs, 35(9), 1608-1615. https://doi.org/10.1377/hlthaff.2015.1457

Cherlin, A., Cumberworth, E., Morgan, S. P., \& Wimer, C. (2013). The Effects of the Great Recession on Family Structure and Fertility. The Annals of the American Academy of Political and Social Science, 650, 214-231. https://doi.org/10.1177/0002716213500643

Chetty, R., Friedman, J. N., Hendren, N., Stepner, M., \& Opportunity Insights Team. (2020). The economic impacts of COVID-19: evidence from a new public database built using private sector data. Retrieved from https://opportunityinsights.org/wp-content/uploads/2020/05/tracker_paper.pdf

Collins, C., Landivar, L. C., Ruppanner, L., \& Scarborough, W. J. (2020). COVID-19 and the gender gap in work hours. Gender, Work \& Organization, gwao.12506. https://doi.org/10.1111/gwao.12506

Coombs, L. C. (1974). The measurement of family size preferences and subsequent fertility. Demography, 11(4), 587-611. https://doi.org/10.2307/2060472

Currie, J., \& Schwandt, H. (2014). Short- And long-term effects of unemployment on fertility. Proceedings of the National Academy of Sciences of the United States of America, 111(41), 14734-14739. https://doi.org/10.1073/pnas.1408975111

Dalton, V. K., Moniz, M. H., Bailey, M. J., Admon, L. K., Kolenic, G. E., Tilea, A., \& Fendrick, A. M. (2020). Trends in birth rates after elimination of cost sharing for contraception by the patient protection and affordable care act. JAMA Network Open, 3(11), e2024398. https://doi.org/10.1001/jaman etworkopen.2020.24398

Dwyer, K., Minton, S., Kwon, D., \& Weisner, K. (2020). Key cross-state variations in CCDF policies as of October 1, 2019. Retrieved from https://ccdf.urban.org.

Easterlin, R. A., Pollak, R., \& Wachter, M. L. (1980). Toward a more general economic model of fertility determination: endogenous preferences and natural fertility. Retrieved from https://www.nber.org/ chapters/c9664.pdf

Efron, B., \& Tibshirani, R. J. (1993). An Introduction to the Bootstrap. Chapman and Hall.

Fowler, C., Gabel, J., \& Lasater, B. (2021). Title X family planning annual report: 2020 national summary. Retrieved from https://opa.hhs.gov/research-evaluation/title-X-services-research/family-plann ing-annual-report/family-planning-0 
Fowler, C, Gable, J., Lasater, B., \& Asman, K. (2020). Title X family planning annual report: 2019 national summary. Retrieved from https://opa.hhs.gov/research-evaluation/title-X-services-research/ family-planning-annual-report/family-planning-0

Fowler, Christina, Gable, J., Wang, J., Lasater, B., \& Wilson, E. (2019). Family planning annual report: 2018 national summary. Retrieved from https://opa.hhs.gov/research-evaluation/title-X-servicesresearch/family-planning-annual-report/family-planning-0

Frost, J. J., Frohwirth, L. F., Blades, N., Zolna, M. R., Douglas-Hall, A., \& Bearak, J. (2017). Publicly Funded Contraceptive Services at U.S. Clinics, 2015. New York.

Gemmill, A., \& Hartnett, C. S. (2020). Demographic drivers of the post-recessionary fertility decline and the future of U.S. fertility. https://doi.org/10.31235/OSF.IO/2U78X

Hainmueller, J. (2011). Entropy balancing for causal effects: A multivariate reweighting method to produce balanced samples in observational studies. Political Analysis, 16, 25-46. https://doi.org/10. 1093/pan/mpr025

Hasstedt, K. (2017). Understanding planned parenthood's critical role in the nation's family planning safety net. Guttmacher Policy Review, 20. Retrieved from https://www.guttmacher.org/sites/default/ files/article_files/gpr2001216.pdf

Heisel, E., Kolenic, G. E., Moniz, M. M., Kobernik, E. K., Minadeo, L., Kamdar, N. S., \& Dalton, V. K. (2018). Intrauterine device insertion before and after mandated health care coverage: The importance of baseline costs. Obstetrics and Gynecology, 131(5), 843-849. https://doi.org/10.1097/AOG. 0000000000002567

Kaiser Family Foundation. (2020). Health insurance coverage of females 19-64. Retrieved December 4, 2020, from https://www.kff.org/other/state-indicator/health-insurance-coverage-of-nonelderly-adultfemales $/$ ?activeTab $=$ graph $\&$ currentTimeframe $=0 \&$ startTimeframe $=11 \&$ selectedRows $=\% 7 \mathrm{~B} \%$ 22wrapups \%22:\%7B\%22united-states\%22:\%7B\%7D\%7D\%7D\&sortModel=\%7B \%22colId $\% 22: \%$ 22Location $\% 22, \% 22$ sort $\% 22: \% 22$ asc $\% 22 \% 7 \mathrm{D}$

Kearney, M., \& Levine, P. (2020a). Half a million fewer children? The coming COVID baby bust. Retrieved from https://www.brookings.edu/research/half-a-million-fewer-children-the-coming-covid-babybust/

Kearney, M., \& Levine, P. (2020b). The coming COVID-19 baby bust: Update. Retrieved from https:// www.brookings.edu/blog/up-front/2020b/12/17/the-coming-covid-19-baby-bust-update/

Kearney, M. S., \& Levine, P. B. (2009). Subsidized contraception, fertility, and sexual behavior. The Review of Economics and Statistics, 91(1), 137-151.

Lindberg, L. D., VandeVusse, A., Mueller, J., \& Kirstein, M. (2020a). Early impacts of the COVID19 Pandemic: Findings from the 2020 a guttmacher survey of reproductive health experiences. Retrieved from https://www.guttmacher.org/report/early-impacts-covid-19-pandemic-findings2020a-guttmacher-survey-reproductive-health

Lindberg, L., Kost, K., Maddow-Zimet, I., Desai, S., \& Zolna, M. (2020b). Abortion reporting in the United States: an assessment of three national fertility surveys. Demography, 57(3), 899-925. https://doi.org/10.1007/S13524-020-00886-4

Lindo, J. M. (2010). Are children really inferior goods? Journal of Human Resources, 45(2), 301-327. https://doi.org/10.3368/jhr.45.2.301

Lindo, J. M., \& Packham, A. (2017). How much can expanding access to long-acting reversible contraceptives reduce teen birth rates? American Economic Journal: Economic Policy, 9(3), 348-376. https://doi.org/10.1257/pol.20160039

Linnakaari, R., Helle, N., Mentula, M., Bloigu, A., Gissler, M., Heikinheimo, O., \& Niinimäki, M. (2019). Trends in the incidence, rate and treatment of miscarriage-nationwide register-study in Finland, 1998-2016. Human Reproduction, 34(11), 2120-2128. https://doi.org/10.1093/humrep/ dez211

Lu, Y., \& Slusky, D. J. G. (2019). The impact of women's health clinic closures on fertility. American Journal of Health Economics, 5(3), 334-359. https://doi.org/10.1162/ajhe_a_00123

National Family Planning \& Reproductive Health Association. (2020). Key facts about title X. Retrieved December 3, 2020, from https://www.nationalfamilyplanning.org/title-X_title-X-key-facts

NYT Editorial Board. (2019). Birth control gets caught up in the abortion wars. The New York Times. Retrieved from https://www.nytimes.com/2019/02/26/opinion/title-X-rule.html

Planned Parenthood Federation of America. (2019). By the Numbers. Retrieved from https://www.plann edparenthood.org/uploads/filer_public/3a/df/3adfdb04-b7f6-420f-a8e7-7284e39f13cc/190124bythenumbers-v01.pdf 
Planned Parenthood Federation of America. (2020). Who we are: Black communities. Retrieved from https://www.plannedparenthood.org/uploads/filer_public/04/da/04da4f8f-7941-4086-a9d9-1f8de e74bddb/200225-who-we-are-black-communities-d01.pdf

Planned Parenthood of Michigan. (2021). Health Center Info 2020 Statewide: 16 Health Centers

Schaller, J. (2016). Booms, Busts, and Fertility. Journal of Human Resources, 51(1), 1-29. https://doi. org/10.3368/JHR.51.1.1

Schaller, J., Fishback, P., \& Marquardt, K. (2020). Local economic conditions and fertility from the great depression through the great recession. AEA Papers and Proceedings, 110, 236-240. https://doi.org/ 10.1257/pandp.20201109

Schneider, D., \& Hastings, O. P. (2015). Socioeconomic variation in the effect of economic conditions on marriage and nonmarital fertility in the united states: evidence from the great recession. Demography, 52(6), 1893-1915.

Shorto, R. (2006, May 7). Contra-contraception. The New York Times Magazine. Retrieved from https:// www.nytimes.com/2006/05/07/magazine/07contraception.html

Trussell, J. (2011). Contraceptive failure in the United States. Contraception, 83, 397-404. https://doi. org/10.1016/j.contraception.2011.01.021

US Census Bureau. (2019). State and Local General Expenditures, Per Capita. Retrieved October 13, 2021, from Annual Survey of State and Local Government Finances, Compiled by the UrbanBrookings Tax Policy Center website: https://www.taxpolicycenter.org/statistics/state-and-localgeneral-expenditures-capita

Venator, J., \& Fletcher, J. (2021). Undue burden beyond texas: An analysis of abortion clinic closures, births, and abortions in wisconsin. Journal of Policy Analysis and Management, 40(3), 774-813. https://doi.org/10.1002/PAM.22263

Ventura, S. J., Curtin, S. C., \& Abma, J. C. (2012). Estimated pregnancy rates and rates of pregnancy outcomes for the United States, 1990-2008. In National Vital Statistics Reports (Vol. 60). Retrieved from http://www.cdc.gov/nchs/nvss/bridged_race.htm.

Willis, R. J. (1973). A new approach to the economic theory of fertility behavior. Journal of Political Economy, 81(2), S14-S64. Retrieved from https://www.jstor.org/stable/1840411

Zolna, M., \& Lindberg, L. (2012). Unintended Pregnancy: Incidence and Outcomes Among Young Adult Unmarried Women in the United States, 2001 and 2008. Retrieved from https://www.guttmacher. $\mathrm{org} / \mathrm{sites} /$ default/files/report_pdf/unintended-pregnancy-us-2001-2008.pdf

Publisher's Note Springer Nature remains neutral with regard to jurisdictional claims in published maps and institutional affiliations. 